\title{
Action of protoporphyrin-IX (PP-IX) in the lifespan of Drosophila melanogaster deficient in endogenous antioxidants, Sod and Cat
}

\author{
Emilio Pimentel $^{1^{\star}}$, Luz M. Vidal ${ }^{1}$, Martha Patricia Cruces ${ }^{1}$, Mariusz Krzysztof Janczur $^{2}$ \\ ${ }^{1}$ Departamento de Biología, Instituto Nacional de Investigaciones Nucleares (ININ), Ocoyoacac, México; \\ *Corresponding Author: emilio.pimentel@inin.gob.mx \\ ${ }^{2}$ Facultad de Ciencias, Universidad Autónoma del Estado de México, Toluca, México
}

Received 12 August 2013; revised 21 September 2013; accepted 2 October 2013

Copyright (C) 2013 Emilio Pimentel et al. This is an open access article distributed under the Creative Commons Attribution License, which permits unrestricted use, distribution, and reproduction in any medium, provided the original work is properly cited.

\begin{abstract}
Protoporphyirin-IX (PP-IX) is a precursor of the biosynthesis of the hemo group, most of the cytochromes and the chlorophylls. The PP-IX is used for medical purposes, and recently a report indicated that it exhibits a dual action since it can decrease or increase the genetic damage caused by $\mathrm{N}$-nitroso-N-ethylurea (ENU) in somatic cells of Drosophila. PP-IX is known to be able to act as an anti- or pro-oxidant agent. The aim of the present research was to study the role of PP-IX on the lifespan of Drosophila melanogaster, taking into account the fact that increasing levels of ROS can accelerate the aging process. The Canton-S strain (CS) was used as well as Sod and Cat which are deficient in the endogenous enzymes, superoxide dismutase and catalase, respectively. Groups of females and males were treated separately with $5 \mathrm{mg} / \mathrm{ml}$ of PP-IX solution. The comparison of survival curves indicates that this pigment extended the lifespan of CS. In contrast, Sod strain showed that the opposite effect and had no effect in Cat strain. The fact that PP-IX reduces the mean lifespan in Sod deficient strain might suggest a pro-oxidant action of PP-IX, and consequently the cumulating of ROS as a superoxide could have a mutagenic effect as was shown recently. The results presented evidence of the dual effect of PP-IX.
\end{abstract}

Keywords: Protoporphyrin IX (PP-IX); Lifespan; Sod; Cat; Reactive Oxygen Species; Longevity; Drosophila melanogaster

\section{INTRODUCTION}

Aerobic metabolism and exposure to physical or chemical agents of anthropogenic origin generate reactive oxygen species (ROS) that are characterized by an unpaired electron. The excess of ROS in the cell causes oxidative stress which may damage DNA, RNA, proteins and lipids producing degenerative diseases, and may accelerate the normal process of aging [1]. Although many ROS are continuously generated during metabolism, neither cells nor their components are damaged due to the action of the physiological defense enzymes that include the following: superoxide dismutase (Sod), catalase (Cat) and glutathione peroxidase [2].

In addition, the cells can prevent oxidative stress through the action of compounds known as antioxidants that are defined as any substance which, when it is present in concentrations lower than those of an oxidizable substrate, delays or inhibits oxidation [3]. Since many antioxidants are found in food, their levels can increase. The compounds that have been more extensively studied for their antioxidant activity are ascorbic acid, $\alpha$-tocopherol and $\beta$-carotene. These compounds have a similar structure which in most cases is responsible for their activity, and which includes at least an aromatic ring and one or more hydroxyl groups that can act as electron donors [4].

Studies in vitro as well as in vivo have shown that chlorophyll and its semi-synthetic derivative, sodium copper chlorophilin (SCC), are able to decrease or completely inhibit DNA damage induced by both physical [5] or chemical agents [6,7]. From the results obtained with different test systems, it was established that SCC works primarily through three mechanisms: a) as an antioxidant, inactivating free radicals, b) forming complexes with mutagens/carcinogens or their precursors, and c) inhibit- 
ing the enzymes involved in the activation of carcinogens [8]. However, although most of the studies have provided evidence that SCC is an excellent antimutagen and/or anticarcinogen, some others have shown that this compound can increase DNA damage, either spontaneously or induced by other agents [9-11].

Previous studies demonstrated that SCC may act as promoter and inhibitor of the mutagenesis in Drosophila. In our study $48 \mathrm{~h}$-old larvae were pretreated for $24 \mathrm{~h}$ with SCC or sucrose and then treated with chromium (VI) oxide $\left(\mathrm{CrO}_{3}\right)$, gamma rays, N,N-Dimethylhydrazine (DMH) or ENU immediately following completion of the pretreatment period (0-day delay) or delayed 1, 2 or 3 days. After delays of 0 and 1 day, clear evidence was found of a protective effect of SCC. Contrarily, after delays of 2 and 3 days the results showed a reversal effect, in other words that SCC-related genetic damage appeared more frequently than the events in the sucrose control suggesting a promoting effect. This dual effect of SCC with different agents suggested that it does not depend on the mechanism of action of the agent [10]. At present, evidence indicates that both the lower concentrations and the SCC metabolites such as PP-IX are involved in the mutagenic effect, and that copper could be responsible for antimutagenic activity [10].

Protoporphyrin-IX is a precursor of the hemo group, the chlorophylls and most of the cytochromes [12]. Some studies have provided evidence that the PP-IX can act as either pro-oxidant or antioxidant; for example, in the presence of light, PP-IX stimulates lipid peroxidation by $\mathrm{Fe}^{+2}$ and ascorbate [13] whereas lipid peroxidation is inhibited in darkness. Increased levels of Sod were also found in mice treated with PP-IX, suggesting that it induces the formation of superoxide radicals [14]. In rat strain CF1, Sod was rapidly induced after a single dose of PP-IX suggesting that superoxide radicals had been generated [14].

The most accepted hypothesis of aging was proposed by Gerschman [15] and Harman [1] who suggest that aging results from the accumulation of damage caused by free radicals; this is supported with evidence found by different systems [16-21]. The use of strains deficient in the expression of endogenous antioxidants has been practicable in testing the effect of dietary antioxidants in lifespan. Drosophila melanogaster has been extensively used to test the effect of dietary exogenous antioxidants in lifespan because it offers many advantages: its lifespan is short, 80 - 90 days (in laboratory conditions) and no mitotic divisions take place in the adult [22]. In addition, different mutant strains in genes involved in antioxidant defense such as catalase and superoxide dismutase enzymes could be used [16,20]. It is known that through the lifespan of Drosophila the activity of Cat decreases [18,23-25] however, the increased expression of the Cat gene does not extend the lifespan of flies, but rather protects against oxidative stress [26].

Some studies have shown that in both, mice [27] and Drosophila [28] a deficiency of the Mn-Sod gene (Sod2) severely reduces lifespan and increases the degree of oxidative stress which in turn, increases the levels of DNA damage and tumor incidence [29]. Unlike Cat, the over expression of Sod-Cu/Zn in Drosophila increases the lifespan [30,31] proportionally to the activity of the enzyme. Moreover, the simultaneous expression of MnSod and $S o d-\mathrm{Cu} / \mathrm{Zn}$ has an additive effect [32], whereas the simultaneous expression of the enzyme Mn-Sod and Cat does not provide additional benefits [33].

Since free radicals accelerate the aging process, the consumption of antioxidants has been promoted due to its ability to inactivate free radicals. Reports have shown that a concentration of $20 \mu \mathrm{g} / \mathrm{mL}$ of vitamin $\mathrm{E}$, added in the culture medium of Drosophila, increased lifespan by $16 \%$ compared with the control group. However, adverse effects were also detected because its higher concentrations $(200 \mu \mathrm{g} / \mathrm{mL})$ reduced the lifespan significantly [34].

One of the best documented mechanisms of action of SCC is its activity as an antioxidant; it is known to be capable of preventing lipid peroxidation [35,36]. However, as mentioned earlier this compound, as well as PP-IX are capable of inducing genetic damage probably through generation of ROS $[10,14]$. To evaluate this possibility, and based on the fact that increased ROS levels accelerate the aging process, we defined our aim in this research as the assessment of the role of PP-IX in the lifespan of D. melanogaster strains deficient in $\mathrm{CuZn-}$ Sod and Cat.

\section{MATERIALS AND METHODS}

\subsection{Drosophila melanogaster Strains}

Canton-S wild type, Sod and Cat strains were used. The last two were obtained from the Bloomington Drosophila Stock Center. Sod and Cat enzymes constitute an evolutionary conserved ROS defense system against superoxide; Sod converts superoxide anions to $\mathrm{H}_{2} \mathrm{O}_{2}$, and Cat prevents free hydroxyl radical formation by breaking down $\mathrm{H}_{2} \mathrm{O}_{2}$ into oxygen and water.

Sod [n1] red [1]/TM3, Sb [1] Ser [1]: In Drosophila, deficiency of cytoplasmic CuZn-Sod $(\operatorname{Sod} 1)$ in Sod1-null mutants imparts reduced lifespan, neurodegeneration, infertility, and hypersensitivity to further oxidative stress [37-39]. The gene encoding the enzyme is located in chromosome 3 [40]. Homozygotes have a significantly shorter mean and maximum lifespan than normal and are sensitive to paraquat, ionizing radiation and hyperoxia compared to control flies.

Cat [n1]/TM3, Sb [1] Ser [1]: This strain is deficient in the enzyme Cat, the gene encoding the enzyme is also 
found in chromosome 3 , in the region 44.3 [40]. Cat enzyme is involved in the decomposition of $\mathrm{H}_{2} \mathrm{O}_{2}$ generated during cellular metabolism [41]. Only about $10 \%$ of homozygous Cat [n1] flies eclose from their pupal cases. Homozygous Cat [n1] mutants also show a reduced lifespan, living half as long as wild type flies [42].

Three groups of 25 males and virgin females $16 \mathrm{~h}$ old were placed separately for $24 \mathrm{~h}$ in homeopathic vials $(10.5 \times 2.4 \mathrm{~cm})$ containing $0.7 \mathrm{mg}$ of Drosophila instant medium (Formula 4 - 24 Carolina Biological Supply Co.) with $2.5 \mathrm{~mL}$ of tap water or $5 \mathrm{mg} / \mathrm{mL}$ solution of PP-IX. In all, 100 to 225 females or males were tested. Three experiments were performed for each group ( 0 and PPIX). Twice a week dead flies were counted, and live individuals were transferred to vials with freshly corresponding treatment. The PP-IX disodium salt (CAS 50865-01-5) was purchased from Sigma Chemical Company (St. Louis, MO).

\subsection{Statistical Analysis}

The Kaplan-Meier test was used to obtain the cumulative survival curves for each experimental group, and for each sex. Data for survival were plotted and curves were compared using the Wilcoxon test (XLSTAT software) [43]. The General Linear Model (GLM) was used to determine any interactions between sex, strains or treatment.

\section{RESULTS}

Based on the toxicity test in which three concentrations for PP-IX were tested $(0.5,5$ and $50 \mathrm{mg} / \mathrm{mL}$.), we found that the $5 \mathrm{mg} / \mathrm{mL}$ concentration was appropriate for chronic treatment in adults. The mean lifespan (MLS) and maximum lifespan (ML) for each sex and treatment were evaluated. MLS is the time where half of the treated individuals died and ML is the total lifespan of individuals.

Table 1 shows the values of both traits of each tested strain. The analysis of variance (ANOVA) at 95\% confidence showed significant differences among strains with a relation: $S o d<C a t<C S$ (see Figure 1.). The treatment with PP-IX significantly prolonged the MLS of females (by 17.4 days) and males (by 9.7 days.) in $C S$ as well as Cat (by 1.6 and 3.2 days for females and males, respecttively.); however, in the latter strain no noteworthy differences were found. In contrast, PP-IX shortened the MLS significantly in both sexes of Sod strain, where the females exhibited a shorter MLS (12 days.) than males (7 days.). Regarding the ML, PP-IX reduced it significantly only in the Sod strain; the reduction of ML was different between females (25 days less.) and males (11 days less.) with respect to the control. No significant differences were found between sex in CS and Cat strains.
Figure 2 shows the survival curves for each strain separately by sex after chronic treatment with PP-IX; data corresponding to females are given in the left panel and for males in the right one. Taking together data for females and males, the results reflect that PP-IX increases the MLS by 13.5 days (26\%) in $C S$, by 2 days $(5 \%)$ in $C a t$ but reduces it in $\operatorname{Sod}$ by 10 days $(26 \%)$ with respect to the control.

\section{DISCUSSION}

Longevity is a quantitative trait, with continuous phenotypic variation attributable to the joint segregation of

Table 1. Effect of chronic treatment with $5 \mathrm{mg} / \mathrm{ml}$ of PP-IX on the lifespan of CS, Sod and Cat strains.

\begin{tabular}{|c|c|c|c|c|c|c|}
\hline Strain & Sex & $\begin{array}{c}\text { Chronic } \\
\text { Treatment } \\
\text { PP-IX } \\
(5 \mathrm{mg} / \mathrm{mL})\end{array}$ & $\mathrm{n}$ & $\begin{array}{c}\text { MLS } \\
\text { (days) } \pm S E\end{array}$ & $\begin{array}{c}\text { ML } \\
\text { [days] }\end{array}$ & $\begin{array}{c}P \text { value } \\
(0 \text { vs. } \\
P P-I X)\end{array}$ \\
\hline \multirow[t]{4}{*}{$C S$} & 우 & 0 & 225 & $50.7 \pm 2.4$ & 84 & \\
\hline & & PP-IX & 150 & $68.1 \pm 3.0$ & 84 & $<0.0001$ \\
\hline & $\sigma^{\lambda}$ & 0 & 225 & $53.3 \pm 2.4$ & 84 & \\
\hline & & PP-IX & 150 & $63.0 \pm 0.1$ & 84 & $<0.0001$ \\
\hline \multirow[t]{4}{*}{ Sod } & q & 0 & 200 & $41.8 \pm 2.6$ & 70 & \\
\hline & & PP-IX & 125 & $29.6 \pm 3.3$ & 45 & $<0.0001$ \\
\hline & $\widehat{0}$ & 0 & 200 & $36.2 \pm 2.6$ & 49 & \\
\hline & & PP-IX & 125 & $29.0 \pm 3.3$ & 38 & $<0.0001$ \\
\hline \multirow[t]{4}{*}{ Cat } & 우 & 0 & 100 & $44.9 \pm 3.7$ & 59 & \\
\hline & & PP-IX & 150 & $46.5 \pm 3.0$ & 63 & n.s. \\
\hline & $\hat{0}$ & 0 & 125 & $43.2 \pm 3.3$ & 63 & \\
\hline & & PP-IX & 150 & $46.4 \pm 3.0$ & 66 & n.s. \\
\hline
\end{tabular}

$\mathrm{n}=$ Number of individuals tested, MLS $=$ Mean lifespan and ML $=$ Maximum lifespan. The MLS were calculated from the general linear model (least square means). $\mathrm{P}$ values were obtained from comparisons between the survival proportion curves. The confidence intervals of MLS were obtained from the Kaplan-Meir analysis.

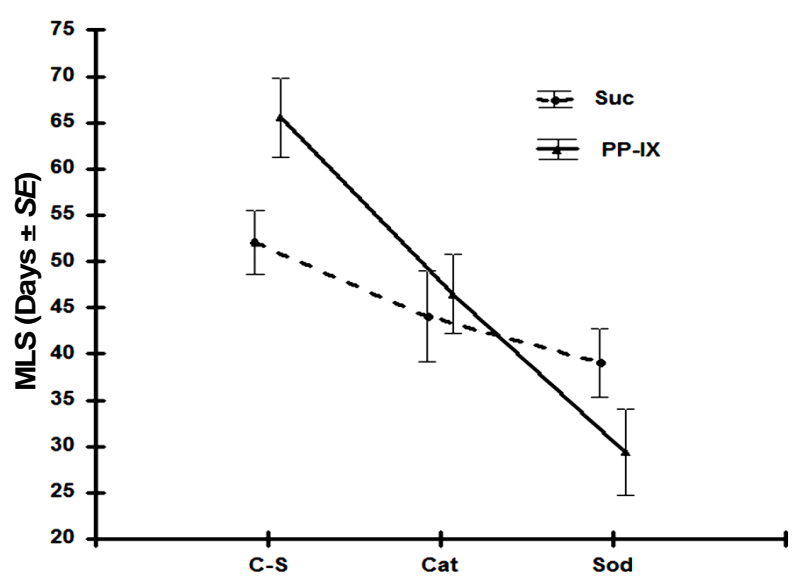

Figure 1. Mean lifespan (MLS) relationship between strains. 

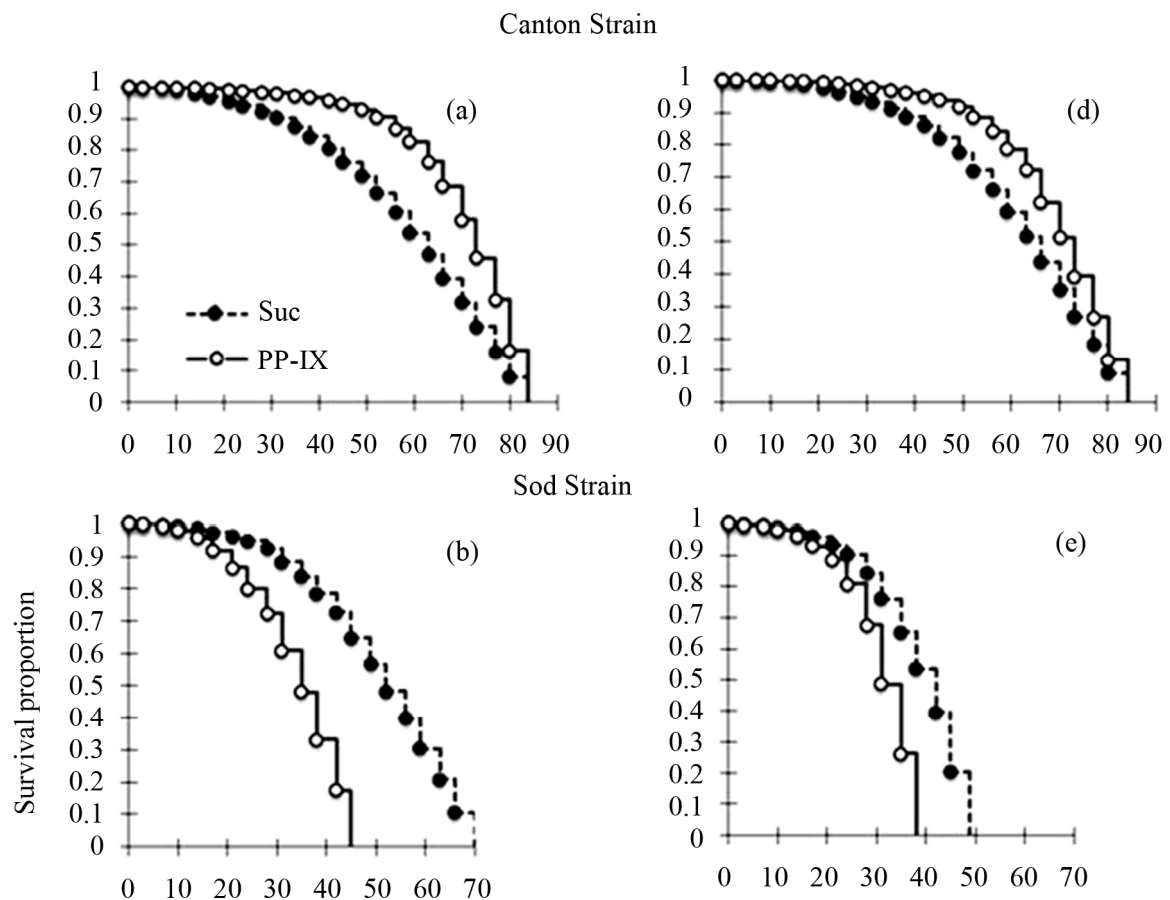

Cat Strain
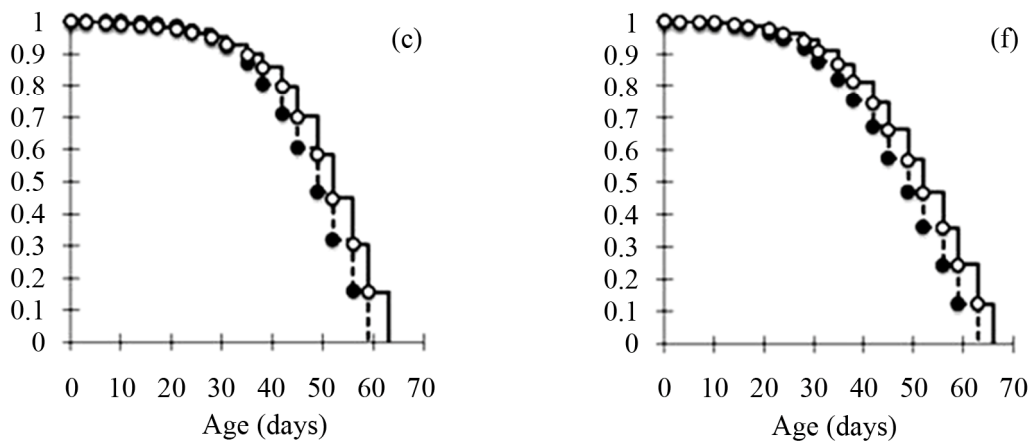

Figure 2. Represents the survival for females (a), (b), (c) and for males (d), (e), (f) Greenwood confidence intervals were employed. Data for survival were plotted and curves were compared using the Wilcoxon test (XLSTAT software) (Addinsoft 2011). Log-rank, Wilcoxon and Tarone-Ware analysis showed a significant difference $(p<0.0001)$ when treatments PP-IX and control were compared for each sex of strain. Probability level was: alpha $=0.05$.

multiple interacting quantitative trait loci and with effects that are highly sensitive to the environment. $D$. melanogaster has been a historically important system for investigating the genetic basis of longevity, which relies on two sources: its powerful genetic tool as a model system, and a natural ecology that provides substantial genetic variation across significant environmental heterogeneity.

In a previous study PP-IX was shown to be able to act as an antimutagen immediately after being administrated to the flies and as a mutagen a few days later [10]. One possible explanation of this effect is that PP-IX provokes damage through generation of ROS. The present study showed that in Sod-deficient strain, chronic treatment with PP-IX reduced the MLS by 12 days for females and by 7 days for males. The ML was shorter by 25 days for females and by 11 days for males. Nevertheless, neither MLS nor ML was affected in Cat-deficient individuals.

These results are in accordance with those reported by Lebovitz et al. [37] in mice and by Duttaroy [28] in Drosophila who showed that the deficiency in the mitochondrial Mn-Sod gene significantly reduces life expectancy due to the increase of the superoxide radical. The same was observed in the absence of the gene encoding the cytosolic CuZn-Sod, but the effect was not as severe as when a deficiency of mitochondrial Sod occurs. It is 
likely that under those conditions PP-IX produces no action on the superoxide generated by the radiation, but probably acts as a pro-oxidant generating superoxide as demonstrated by Afonso et al. [14].

Another example that supports this hypothesis is that PP-IX has been used for several years in photodynamic therapy $[14,44-46]$. This is so due to its ability to induce superoxide radicals that react with molecular oxygen producing peroxide radicals which cause lipid peroxidetion, and leading to different cell damages such as structural changes of the cell membrane, damage to proteins, inactivation of receptors, enzymes and ion channels, all of which can lead to cell death [47].

The protective activity of PP-IX observed in the CS strain in this study could be the result of the elimination of free radicals, particularly $\mathrm{H}_{2} \mathrm{O}_{2}$. Afonso et al. [14] found that Cat activity increased $30 \%$ in rats of the strain $\mathrm{CF} 1,2 \mathrm{~h}$ after the injection of PP-IX, with the decrease in $\mathrm{H}_{2} \mathrm{O}_{2}$ levels. Although the results obtained with $\mathrm{Cat}$ strain showed a minimum increase in the MLS and ML, in the wild type strain its effect was more evident; PP-IX increased the MLS by $26 \%$ compared to the control. However, a report indicated that the over expression of Cat by $80 \%$ did not increase the lifespan of Drosophila, but protected it against oxidative stress [48]. Furthermore, Griswold et al. [49] molecularly characterized six alleles and found that Cat [n2], Cat [n3], Cat [n5] and Cat [n6] reduced the Cat activity, viability and normal longevity, but the alleles Cat [n1] and Cat [n4] showed no activity of Cat, yet longevity and viability were reduced. Mackay et al. [50] showed that Cat null allele caused a significant increase in the frequency of spontaneous mutations. The increase in MLS in CS and Cat could be attributable to the antimutagenic effect reported by other authors [5, 51-53], who suggest that the protective effect of both PP-IX and SCC, (porphyrin bound to $\mathrm{Cu}^{+2}$.) is due to their ability to arrest free radicals generated by radiation and to increase the expression of endogenous antioxidants [54].

Although the PP-IX treatment reduced the MLS in the Sod-deficient strain (Probably because of its pro-oxidant action inducing the formation of $\mathrm{O}^{2-}$ radicals, the $\mathrm{H}_{2} \mathrm{O}_{2}$ produced by this increase in superoxide.), the antioxidant action of PP-IX could be added to the action of glutathione peroxidase enzyme which can also reduce $\mathrm{H}_{2} \mathrm{O}_{2}$.

According to the effect of PP-IX on both the wild type $C S$ and the Cat strain, we suggest three possible mechanisms of action: a) as inductor of the antioxidant enzymes to achieve normal levels of activity; b) as an antioxidant, reducing the levels of peroxide; and c) both actions occurring simultaneously in the organism provoking an increase in the lifespan of the treated organisms. The $C S$ strain is the best evidence of the c) mechanism, since in this strain PP-IX delayed death and strongly increased MLS at birth in both sexes by 13.5 days.

\section{ACKNOWLEDGEMENTS}

This research was supported by a grant from Consejo Nacional de Ciencia y Tecnología (CONACyT), México, Grant Number 167461 and involved in part research carried out by L.M., Vidal to obtain the Master Degree in Environmental Sciences at Universidad Autónoma del Estado de México (UAEM). The authors wish to acknowledge the splendid technical assistance of Hugo Suarez Contreras and Alicia Hernández Arenas.

\section{REFERENCES}

[1] Harman, D. (1956) Aging: A theory based on free radical and radiation chemistry. The Journals of Gerontology, 11, 298-300. http://dx.doi.org/10.1093/geronj/11.3.298

[2] Frei, B., Stocker, R. and Ames, B. (1992) Small molecule antioxidant defenses in human extracellular fluids. In: Scandalios, J., Ed., Molecular Biology of Free Radical Scavenging Systems. Current Communications in Cell and Molecular Biology. Cold Spring Harbor, New York, 23-45.

[3] Halliwell, B. (2006) Oxidative stress and neurodegeneration: Where are we now? Journal of Neurochemistry, 97, 1634-1658.

http://dx.doi.org/10.1111/j.1471-4159.2006.03907.x.

[4] Simic, M.G. and Jovanovic, S.V. (1990) Mechanisms of inactivation of oxygen radicals by dietary antioxidants and their models. Antimutagenesis and anticarcinogenesis mechanisms II, Basic Life Sciences, 52, 127-137.

[5] Zimmering, S., Olvera, O, Hernandez, M.E., Cruces, M.P., Arceo, C. and Pimentel, E. (1990) Evidence for a radioprotective effect of chlorophyllin in Drosophila. Mutation Research, 245, 47-49. http://dx.doi.org/10.1016/0165-7992(90)90024-E.

[6] Cruces, M.P. and Pimentel, A.E. (2006) Antimutagénesis: La clorofilina una alternativa? In: Pimentel, A.E., Ortiz, A. and Breña, M., Ed., Tópicos de Genética, UAEM-SMG, Mexico, 55-75.

[7] Ferguson, L.R. and Philpott, M. (2008) Nutrition and mutagenesis. Annual Review of Nutrition, 28, 313-329. http://dx.doi.org/10.1146/annurev.nutr.28.061807.155449

[8] Ferruzzi, M.G. and Blakeslee, J. (2007) Digestion, absorption, and cancer preventative activity of dietary chlorophyll derivatives. Nutrition Research, 27, 1-12. http://dx.doi.org/10.1016/j.nutres.2006.12.003

[9] Cruces, M.P., Pimentel, E. and Zimmering, S. (2009) Evidence that low concentrations of chlorophyllin $(\mathrm{CH}$ $\mathrm{LN}$ ) increase the genetic damage induced by gamma rays in somatic cells of Drosophila. Mutation Research, 679, 84-86. http://dx.doi.org/10.1016/j.mrgentox.2009.07.004

[10] Pimentel, E., Cruces, M.P. and Zimmering, S. (2011) A study of the inhibition/promotion effects of sodium-copper chlorophyllin (SCC)-mediated mutagenesis in somatic cells of Drosophila. Mutation Research, 722, 52-55. http://dx.doi.org/10.1016/j.mrgentox.2011.03.001 
[11] Romert, L., Curvall, M. and Jenssen, D. (1992) Chlorophyllin is both a positive and negative modifier of mutagenicity. Mutagenesis, 7, 349-355. http://dx.doi.org/10.1093/mutage/7.5.349

[12] Panek, H. and O'Brian, M.R. (2002) A whole genome view of prokaryotic haem biosynthesis. Microbiology, 148, 2273-2282.

[13] Williams, M., Krootjes, B.H., Van Steveninck, J. and Van Der Zee, J. (1994) The pro- and antioxidant properties of protoporphyrin IX. Biochimica et Biophysica Acta $(B B A)$ —Lipids and Lipid Metabolism, 1211, 310-316. http://dx.doi.org/10.1016/0005-2760(94)90155-4

[14] Afonso, S., Vanore, G. and Batlle, A. (1999) Protoporphyrin IX and oxidative stress. Free Radical Research, 31, 161-170. http://dx.doi.org/10.1080/10715769900300711

[15] Gerschman, R., Gilbert, D., Nye, S.W., Dwyer, P. and Fenn, W.O. (1954) Oxygen poisoning and Xirradiation: A mechanism in common. Science, 119, 623-626.

[16] Bray, R.C., Cockle, S.A., Fielden, E.M., Roberts, P.B., Rotilio, G. and Calabrese, L. (1974) Reduction and inactivation of superoxide dismutase by hydrogen peroxide. Biochemical Journal, 139, 43-48.

[17] Sohal, R.S. and Allen, R.G. (1990) Oxidative stress as a causal factor in differentiation and aging: A unifying hypothesis. Experimental Gerontology, 25, 499-522. http://dx.doi.org/10.1016/0531-5565(90)90017-V

[18] Sohal, R. S., Sohal, B.H. and Brunk, U.T. (1990) Relationship between antioxidant defenses and longevity in different mammalian species. Mechanisms of Ageing and Development, 53, 217-227. http://dx.doi.org/10.1016/0047-6374(90)90040-M

[19] Sohal, R.S., Agarwal, S. and Sohal, B.H. (1995) Oxidative stress and aging in the Mongolian gerbil (Meriones unguiculatus). Mechanisms of Ageing and Development, 81, $15-25$. http://dx.doi.org/10.1016/0047-6374(94)01578-A

[20] Helfand, S.L. and Rogina, B. (2003) Genetics of aging in the fruit fly, Drosophila melanogaster. Annual Review of Genetics, 37, 329-348. http://dx.doi.org/10.1146/annurev.genet.37.040103.09521 $\underline{1}$

[21] Bernard, G.R., Wheeler, A.P., Arons, M.M., Morris, P.E., Paz, H.L., Russell, J.A. and Wright, P.E. (1997) A trial of antioxidants $\mathrm{N}$-acetylcysteine and procysteine in ARDS. The Antioxidant in ARDS Study Group. Chest, 112, 164172. http://dx.doi.org/10.1378/chest.112.1.164

[22] Bozuck, A. N. (1972) DNA synthesis in the absence of somatic cell division associated with ageing in Drosophila subobscura. Experimental Gerontology, 7, 147-156. http://dx.doi.org/10.1016/0531-5565(72)90022-8

[23] Ballarini, F., Biaggi, M., Ottolenghi, A. and Sapora, O. (2002) Cellular communication and bystander effects: A critical review for modelling low-dose radiation action. Mutation Research, 501, 1-12. http://dx.doi.org/10.1016/S0027-5107(02)00010-6

[24] Sohal, R. S., Donato, H. and Biehl, E. R. (1981) Effect of age and metabolic rate on lipid peroxidation in the housefly, Musca domestica L. Mechanisms of Ageing and De- velopment, 16, 159-167.

http://dx.doi.org/10.1016/0047-6374(81)90092-0

[25] Sohal, R.S. and Allen, R.G. (1986) Relationship between oxygen metabolism, aging and development. Advances in Free Radical Biology \& Medicine, 2, 117-160. http://dx.doi.org/10.1016/S8755-9668(86)80026-6

[26] Orr, W.C. and Sohal, R.S. (1994) Extension of life-span by overexpression of superoxide dismutase and catalase in Drosophila melanogaster. Science, 263, 1128-1130. http://dx.doi.org/10.1126/science.8108730

[27] Lebovitz, R.M., Zhang, H., Vogel., H., Cartwright, J, Jr., Dionne, L., Lu, N., Huang, S. and Matzuk, M.M. (1996) Neurodegeneration, myocardial injury, and perinatal death in mitochondrial superoxide dismutase-deficient mice. Proceedings of the National Academy of Sciences of the United States of America, 93, 9782-9787. http://dx.doi.org/10.1073/pnas.93.18.9782

[28] Duttaroy, A., Paul, A., Kundu, M. and Belton, A. (2003) A Sod2 null mutation confers severely reduced adult lifespan in Drosophila. Genetics, 165, 2295-2299.

[29] Van Remmen, H., Ikeno, Y., Hamilton, M., Pahlavani, M., Wolf, N., Thorpe, S.R., Alderson, N.L., Baynes, J.W., Epstein, C.J., Huang, T.T., Nelson, J., Strong, R. and Richardson, A. (2003) Life-long reduction in MnSOD activity results in increased DNA damage and higher incidence of cancer but does not accelerate aging. Physiological Genomics, 16, 29-37.

http://dx.doi.org/10.1152/physiolgenomics.00122.2003

[30] Parkes, T.L., Elia, A.J., Dickinson, D., Hilliker, A.J., Phillips, J.P. and Boulianne, G.L. (1998) Extension of Drosophila lifespan by overexpression of human SOD1 in motorneurons. Nature Genetics, 19, 171-174. http://dx.doi.org/10.1038/534

[31] Phillips, J.P., Parkes, T.L. and Hilliker, A. J. (2000) Targeted neuronal gene expression and longevity in Drosophila. Experimental Gerontology, 35, 1157-1164. http://dx.doi.org/10.1016/S0531-5565(00)00117-0

[32] Sun, J., Molitor, J. and Tower, J. (2004) Effects of simultaneous over-expression of $\mathrm{Cu} / \mathrm{ZnSOD}$ and MnSOD on Drosophila melanogaster lifespan. Mechanisms of Ageing and Development, 125, 341-349.

[33] Sun, J., Folk, D., Bradley, T.J. and Tower, J., (2002) Induced overexpression of mitochondrial Mn-superoxide dismutase extends the lifespan of adult Drosophila melanogaster. Genetics, 161, 661-672.

[34] Miquel, J., Fleming J. and Economos A.C. (1982) Antioxidants, metabolic rate and aging in Drosophila. Archives of Gerontology and Geriatrics, 1, 159-165. http://dx.doi.org/10.1016/0167-4943(82)90016-4

[35] Bulmer, A. C., Ried, K., Blanchfield, J.T. and Wagner, K.H. (2008) The anti-mutagenic properties of bile pigments. Mutation Research, 658, 28-41. http://dx.doi.org/10.1016/j.mrrev.2007.05.001

[36] Odin, A.P. (1997) Antimutagenicity of the porphyrins and non-enzyme porphyrin-containing proteins. Mutation Research, 387, 55-68. http://dx.doi.org/10.1016/S1383-5742(97)00023-9

[37] Woodruff, R.C., Phillips, J.P. and Hilliker, A.J. (2004) In- 
creased spontaneous DNA damage in $\mathrm{Cu} / \mathrm{Zn}$ superoxide dismutase (SOD1) deficient Drosophila. Genome, 47, 10291035. http://dx.doi.org/10.1139/g04-083

[38] Kirby, K., Jensen, L.T., Binnington, J., Hilliker, A.J., Ulloa, J., Culotta, V.C. and Phillips, J.P. (2008) Instability of superoxide dismutase 1 of Drosophila in mutants deficient for its cognate copper chaperone. The Journal of Biological Chemistry, 283, 35393-35401. http://dx.doi.org/10.1074/jbc.M807131200

[39] Sun, X., Komatsu, T., Lim, J., Laslo, M., Yolitz, J., Wang, C., Poirier, L., Alberico, T. and Zou, S. (2012) Nutrient-dependent requirement for SOD1 in lifespan extension by protein restriction in Drosophila melanogaster. Aging Cell, 11, 783-793.

[40] Lindsley, D.L. and Zimm, G.G. (1992) The genome of Drosophila melanogaster. Academic Press, La Jolla.

[41] Céspedes-Miranda, E.M., Hernández-Lantigua, I. and Llópiz-Janer, N. (1996) Enzimas que participan como barreras fisiológicas para eliminar los radicales libres: II. Catalasa. Revista Cubana de Investigaciones Biomédicas, 15, 1-7.

[42] Missirlis, F., Rahlfs, S., Dimopoulos, N., Bauer, H., Becker, K., Hilliker, A., Phillips, J.P. and Jackle, H. (2003) A putative glutathione peroxidase of Drosophila encodes a thioredoxin peroxidase that provides resistance against oxidative stress but fails to complement a lack of catalase activity. Biological Chemistry, 384, 463-472. http://dx.doi.org/10.1515/BC.2003.052

[43] Addinsoft (2011) XLSTAT. Addinsoft, USA.

[44] Gibson, S.L. and Hilf, R. (1985) Interdependence of fluence, drug dose and oxygen on hematoporphyrin derivative induced photosensitization of tumor mitochondria. Photochemistry and Photobiology, 42, 367-373. http://dx.doi.org/10.1111/j.1751-1097.1985.tb01583.x

[45] Moan, J. and Sommer, S. (1985) Oxygen dependence of the photosensitizing effect of hematoporphyrin derivative in NHIK 3025 cells. Cancer Research, 45, 1608-1610.

[46] Weishaupt, K.R., Gomer, C.J. and Dougherty, T.J. (1976)
Identification of singlet oxygen as the cytotoxic agent in photoinactivation of a murine tumor. Cancer Research, 36, 2326-2329.

[47] Girotti, A.W. (1985) Mechanisms of lipid peroxidation. Journal of Free Radicals in Biology \& Medicine, 1, 87-95. http://dx.doi.org/10.1016/0748-5514(85)90011-X

[48] Orr, W.C. and Sohal, R.S. (1992) The effects of catalase gene overexpression on lifespan and resistance to oxidative stress in transgenic Drosophila melanogaster. Archives of Biochemistry and Biophysics, 297, 35-41. http://dx.doi.org/10.1016/0003-9861(92)90637-C

[49] Griswold, C.M., Matthews, A.L., Bewley K.E. and Mahaffey, J.W. (1993) Molecular characterization and rescue of acatalasemic mutants of Drosophila melanogaster. Genetics, 134, 781-788.

[50] Mackay, T.F.C., Lyman, R.F. and Jackson, M.S. (1992) Effects of P-element insertions on quantitative traits in Drosophila melanogaster. Genetics, 130, 315-332.

[51] Boloor, K.K., Kamat, J.P. and Devasagayam, T.P. (2000) Chlorophyllin as a protector of mitochondrial membranes against gamma-radiation and photosensitization. Toxico$\log y$, 155, 63-71.

http://dx.doi.org/10.1016/S0300-483X(00)00278-X

[52] Kamat, J.P., Boloor, K.K and Devasagayam, T.P. (2000) Chlorophyllin as an effective antioxidant against membrane damage in vitro and ex vivo. Biochimica et Biophysica Acta (BBA)-Molecular and Cell Biology of Lipids, 1487, 113-127. http://dx.doi.org/10.1016/S1388-1981(00)00088-3

[53] Pimentel, E., Cruces, M.P. and Zimmering, S. (1999) On the persistence of the radioprotective effect of chlorophyllin (CHLN) in somatic cells of Drosophila. Mutation Research, 446, 189-192. http://dx.doi.org/10.1016/S1383-5718(99)00182-5

[54] Wolff, S. (1996) Aspects of the adaptive response to very low doses of radiation and other agents. Mutation Research, 358,135-142.

http://dx.doi.org/10.1016/S0027-5107(96)00114-5 